\title{
Use of Hydroxyapatite Doping to Enhance Responsiveness of Heat-Inducible Gene Switches to Focused Ultrasound
}

Mario L. Fabiilli, ${ }^{1,2}$, Rahul A. Phanse ${ }^{3,4}$, Alexander Moncion ${ }^{1,2}$, J. Brian Fowlkes ${ }^{1,2,3}$, and Renny T. Franceschi ${ }^{3,4,5}$

${ }^{1}$ Department of Radiology, University of Michigan Health System, Ann Arbor, MI, USA

${ }^{2}$ Applied Physics Program, University of Michigan, Ann Arbor, MI, USA

${ }^{3}$ Department of Biomedical Engineering, University of Michigan, Ann Arbor, MI, USA

${ }^{4}$ School of Dentistry, University of Michigan, Ann Arbor, MI, USA

${ }^{5}$ Department of Biological Chemistry, University of Michigan Medical School, Ann Arbor, MI, USA

Corresponding Author

Mario Fabiilli

University of Michigan

3226A Medical Sciences Building I

1301 Catherine Street

Ann Arbor, MI 48109

Tel: 734-647-9326

Fax: 734-764-8541

Email: mfabiill@umich.edu 


\section{Abstract}

Recently, we demonstrated that ultrasound-based hyperthermia can activate cells containing a heat-activated and ligand-inducible gene switch in a spatio-temporally controlled manner. These engineered cells can be incorporated into hydrogel scaffolds (e.g., fibrin) for in vivo implantation, where ultrasound can be used to non-invasively pattern transgene expression. Due to their high water content, the acoustic attenuation of fibrin scaffolds is low. Thus, long ultrasound exposures and high acoustic intensities are needed to generate sufficient hyperthermia for gene activation. Here, we demonstrate that the attenuation of fibrin scaffolds and the resulting hyperthermia achievable with ultrasound can be increased significantly by doping the fibrin with hydroxyapatite $(\mathrm{HA})$ nanopowder. The attenuation of a $1 \%(\mathrm{w} / \mathrm{v})$ fibrin scaffold with $5 \%(\mathrm{w} / \mathrm{v}) \mathrm{HA}$ was similar to soft tissue. Transgene activation of cells harboring the gene switch occurred at lower acoustic intensities and shorter exposures when the cells were encapsulated in HA-doped fibrin scaffolds versus undoped scaffolds. Inclusion of HA in the fibrin scaffold did not affect the viability of the encapsulated cells.

Keywords: ultrasound, hyperthermia, hydrogel, fibrin, attenuation, gene therapy, hydroxyapatite 


\section{Introduction}

Ultrasound (US)-induced thermal therapies can be broadly divided into two categories based on the thermal dose. In ablative therapy, focused US is used to increase the temperature of tissue above $55^{\circ} \mathrm{C}$, thus causing irreversible tissue damage via coagulative necrosis. In contrast, US can generate hyperthermic conditions (i.e., $40-45^{\circ} \mathrm{C}$ ), which typically do not yield direct cytotoxicity. Rather, hyperthermia can be used in various ways that are beneficial in the treatment of solid tumors including: 1) increasing vascular permeability, oxygenation, and perfusion (Friedl, et al. 2003, Song, et al. 2005), 2) enhancing the effects of radiation therapy (Franckena, et al. 2009), 3) increasing the cytotoxicity of chemotherapeutic agents (Urano, et al. 1999), and 4) modulating the release of chemotherapeutics from temperature-sensitive liposomes (Escoffre, et al. 2013, Ranjan, et al. 2012).

Hyperthermia can also impact the structure and function of proteins. In response to a thermal insult, heat shock proteins (HSPs) such as HSP70B are up-regulated and act as molecular chaperones, thus stabilizing protein structure and preventing loss of protein bioactivity. Within the field of gene therapy, HSP promoters can be integrated into genetic sequences, thus enabling control of transgene expression using hyperthermia. When incorporated into cells, genetic constructs containing these heat-activated "gene switches" can be stimulated by US conditions that generate hyperthermia (i.e., $43-45^{\circ} \mathrm{C}$ ) (Deckers, et al. 2009). Unlike hyperthermic water baths, US-induced hyperthermia can be generated with tight spatial and temporal control with minimal effects on tissues away from the focal volume, a property that aids in potential clinical translatability. Previous studies demonstrated that US-mediated hyperthermia could regulate gene expression after heat shock gene switches were injected intradermally (Smith, et al. 2002) (Wilson, et al. 2014), intramuscularly (Lu, et al. 2009, Xu, et al. 2004), intrarenally (Eker, et al. 2011), or uptaken by the liver (Plathow, et al. 2005).

Critical to the successful development of gene therapy is the development of approaches for temporal and spatial control of transgene expression. For example, 
regenerative growth factors must be expressed in spatially and temporally restricted patterns during angiogenesis and osteogenesis. We recently demonstrated that hyperthermia generated using focused US could thermally activate cells containing heat-activated and ligand-inducible gene switches encoding firefly luciferase $(f L u c)$, vascular endothelial growth factor (VEGF), or bone morphogenetic protein 2 (BMP2) (Wilson, et al. 2014). These engineered cells were incorporated into a hydrogel scaffold for in vivo implantation, which is a commonly used strategy with the field of regenerative medicine. Hydrogel scaffolds are typically highly-porous and composed of biodegradable materials that act as an adhesive substrate for cells. Due to their high water content, the acoustic attenuation of hydrogel scaffolds is much lower than soft tissue or bone. Thus, long US exposures and high acoustic intensities are required to generate sufficient hyperthermia within the hydrogel. If the hydrogel scaffold containing the heat shock activated cells is implanted within or adjacent to soft tissue or bone, these tissues could preferentially heat. This minimizes spatial control of transgene activation while also potentially causing heat-related damage in adjacent tissue.

In this work, we demonstrate that the acoustic attenuation of a hydrogel scaffold (i.e., fibrin) can be increased to the level of soft tissue by doping the scaffold with hydroxyapatite (HA, $\left.\mathrm{Ca}_{10}\left(\mathrm{PO}_{4}\right)_{6}(\mathrm{OH})_{2}\right)$ nanoparticles. $\mathrm{HA}$ is the mineral component of bone and aids in both angiogenesis and osteogenesis. HA has been previously incorporated into hydrogels to inhibit cell-mediated compaction, decrease cell migration, and influence viral delivery (Kidd, et al. 2012, Liu and Williams 2010). Fibrin was chosen as the hydrogel due to its high biocompatibility and extensive use in tissue engineering studies. These studies demonstrate that heat shock mediated transgene activation in HA-doped fibrin gels can occur at shorter US exposures and lower acoustic intensities than previously reported (Wilson, et al. 2014). 


\section{Materials and Methods}

\section{Acellular scaffold preparation}

Fibrin scaffolds with $0.5 \%, 1 \%$, or $2 \% \mathrm{w} / \mathrm{v}$ clottable protein were prepared by combining bovine fibrinogen (76\% protein, $92 \%$ clottable protein, Sigma-Aldrich, St. Louis, MO, USA) dissolved in Dulbecco's modified Eagle medium (DMEM) with bovine thrombin (2 U/mL, Thrombin-JMI, King Pharmaceuticals, Bristol, TN, USA) and bovine lung aprotinin $(0.1 \mathrm{U} / \mathrm{mL}$, Sigma-Aldrich). HA-doped fibrin scaffolds were prepared by suspending HA nanopowder (< $200 \mathrm{~nm}$ particle size, $>97 \%$ purity, Sigma-Aldrich) in a 1:3 (v/v) solution of fetal bovine serum (FBS, Atlanta Biologicals, Flowery Branch, GA, USA) and DMEM. The mixture was sonicated

on ice for 60 s using a sonicator (model 450, Branson, Danbury, CT, USA) to disperse the HA aggregates. The HA mixture was combined with bovine fibrinogen dissolved in DMEM, bovine lung aprotinin, and bovine thrombin such that the final concentrations of fibrinogen, aprotinin, and thrombin in the resulting scaffold were $1 \%(\mathrm{w} / \mathrm{v})$ clottable protein, $0.05 \mathrm{U} / \mathrm{mL}$, and $2 \mathrm{U} / \mathrm{mL}$, respectively. All solutions were degased under vacuum prior to polymerization.

For the undoped and HA-doped scaffolds, the fibrin mixture was allowed to polymerize inside custom sample molds made from polyvinyl chloride (PVC) pipe. Each mold consisted of a length of PVC pipe (inner diameter: $34 \mathrm{~mm}$, height: $\sim 10 \mathrm{~mm}$ or $20 \mathrm{~mm}$ ) sealed on both ends with Tegaderm membrane (3M, St. Paul, MN, USA). The scaffolds polymerized for $30 \mathrm{~min}$ at room temperature prior to use.

\section{Measurement of scaffold acoustic properties}

The speed of sound and attenuation of the acellular scaffolds were measured using a broadband pulse technique in an experimental setup similar to Selfridge (1985). A singleelement US transducer (3.5 MHz, diameter: $19.1 \mathrm{~mm}$, f-number: 2, Olympus, Waltham, MA, USA) was positioned in a temperature controlled (i.e., $24.5 \pm 0.5^{\circ} \mathrm{C}$ ), degassed water tank such 
that the focus was perpendicular to the surface of a brass reflector plate. Each scaffold composition was prepared in triplicate at two nominal thicknesses. The thickness of each scaffold was measured using digital calipers and the scaffolds were imaged with B-mode US (10L probe operating at 6.3 MHz, Logiq 9, GE Healthcare, Milwaukee, WI, USA). All scaffold samples were allowed to thermally equilibrate within the tank for at least $1 \mathrm{~h}$ prior to acoustic measurements. For each sample pair, the thinner sample was first carefully placed on the brass plate, such that the transducer position was not disturbed and the beam profile interrogated the scaffold. The transducer was excited using a pulser/receiver (5073PR, Olympus) and the resulting reflection was digitized using an oscilloscope (HDO4934, Teledyne LeCroy, Chestnut Ridge, NY, USA). To account for insertion loss, the process was repeated using the thicker scaffold sample. The speed of sound and attenuation of olive oil, presented similarly to the scaffolds, was also measured as a control due to the availability of published values (Benedito, et al. 2002, Chanamai and McClements 1998, Treeby, et al. 2009).

The acquired radiofrequency $(\mathrm{RF})$ waveforms were analyzed in MATLAB (Mathworks, Natick, MA, USA). The speed of sound was calculated based on time of flight. The attenuation was calculated based on the spectral magnitudes of the RF waveforms using a previously described method (Ping 1999). The slope of the attenuation coefficient (i.e., $\mathrm{dB} /(\mathrm{cm} \bullet \mathrm{MHz})$ ) was computed using a linear fit in the range of 2.3-4.7 $\mathrm{MHz}$ (i.e., $69 \%$ bandwidth).

\section{Measurement of temperature elevation in scaffolds during ultrasound-induced hyperthermia}

Acellular scaffolds were prepared as described above, except that a needle-type thermocouple (diameter: $0.3 \mathrm{~mm}$, type K, Omega Engineering Inc., Stamford, CT, USA) was inserted through the PVC sidewall of the sample mold prior to polymerization. Each scaffold was then fixtured in the degassed water tank and allowed to thermally equilibrate for $30 \mathrm{~min}$. A calibrated, single-element high intensity focused US (HIFU) transducer $(\mathrm{H}-108,2.5 \mathrm{MHz}$, diameter: $60 \mathrm{~mm}$, f-number: 0.83, Sonic Concepts, Bothell, WA, USA) was positioned 
perpendicular to the sample and pulse-echo was used to finely adjust the position of the transducer focus with respect to the tip of the embedded thermocouple. To generate hyperthermia within the scaffold, the transducer was driven by a continuous wave signal generated by a function generator (33500B series, Agilent Technologies, Santa Clara, CA, USA) and amplified by an RF amplifier ( $55 \mathrm{~dB}, \mathrm{~A}-300$, Electronics \& Innovation, Rochester, NY, USA). To minimize the reflection of US energy and prevent the formation of standing waves, a slab of sound absorbing material was placed behind the sample at approximately a $45^{\circ}$ angle. Temperatures were recorded using a thermocouple data logger (TC-08, Pico Technology, Tyler, TX, USA) and associated data acquisition software.

\section{Cell-loaded scaffold preparation}

The heat-activated and rapamycin-dependent gene switches for regulating $f L u c$ as well as the C3H10T1/2 cell line stably expressing the switches are described elsewhere (MartinSaavedra, et al. 2013, Wilson, et al. 2014). Cell-loaded scaffolds were cast in six-well culture plates (Bioflex, Flexcell International, Burlington, NC, USA) that were modified as previously described (Wilson, et al. 2014). To facilitate the eventual removal of the scaffolds from the plate, each well was blocked with complete medium consisting of DMEM with $10 \%$ (v/v) FBS, $10 \mathrm{mM}$ HEPES (Life Technologies, Grand Island, NY, USA), 100 units/mL penicillin (Life Technologies), and $100 \mu \mathrm{g} / \mathrm{mL}$ streptomycin (Life Technologies) prior to scaffold polymerization. Undoped and HA-doped fibrin scaffolds ( $1 \%$ clottable protein, $5 \mathrm{~mL}$ total volume) were prepared as described above except that $10^{6} \mathrm{C} 3 \mathrm{H} 10 \mathrm{~T} 1 / 2$-fLuc cells $/ \mathrm{mL}$ were encapsulated in the scaffolds. The scaffolds were allowed to polymerize in a tissue culture incubator $\left(37^{\circ} \mathrm{C}, 5 \%\right.$ carbon dioxide) for $30 \mathrm{~min}$. After polymerization, each well was fitted with a sterile acrylic platen (Flexcell International), filled with complete medium containing $10 \mathrm{nM}$ rapamycin (LC Laboratories, Woburn, MA, USA), and sealed with a Tegaderm membrane. The scaffolds were placed in the incubator overnight. 


\section{Transgene activation via US-induced hyperthermia}

The following day, the plate containing the cell-loaded scaffolds was submerged in a degassed, heated $\left(37^{\circ} \mathrm{C}\right)$ water tank and allowed to thermally equilibrate for $30 \mathrm{~min}$. The axial focus of the HIFU transducer was positioned perpendicular to the plate and pulse-echo was used to finely adjust the position of the transducer with respect to the scaffold. US-induced hyperthermia was generated in each scaffold as described above. A schematic of the US exposure setup can be found in a previous publication (Wilson, et al. 2014). A 3x3 grid pattern of acoustic exposures was generated in each scaffold, with $5 \mathrm{~mm}$ spacing between exposures. After US exposure, the scaffolds were aseptically removed from the plate, transferred to $60 \mathrm{~mm}$ culture dishes containing complete medium with $10 \mathrm{nM}$ rapamycin, and placed in the tissue culture incubator overnight.

\section{Quantification of fLuc expression}

The following day, D-luciferin substrate (Promega, Madison, WI, USA) was added to the culture dishes at a final concentration of $80 \mu \mathrm{g} / \mathrm{mL}$. After a $30 \mathrm{~min}$ incubation, the bioluminescent signal from the scaffolds was measured on an IVIS Spectrum imaging system (Perkin Elmer, Waltham, MA, USA) at the University of Michigan Center for Molecular Imaging. Quantitative image analysis of $f L u c$ expression was performed using Living Image software (version 4.0, Perkin Elmer). Equally-sized regions of interest (ROIs), corresponding to each US exposure within a scaffold, were drawn and the average radiance within an $\mathrm{ROI}$ and the maximum radiance within an $\mathrm{ROI}$ were calculated. Radiance was expressed as photons $/$ second $/ \mathrm{cm}^{2} /$ steradian $\left(\mathrm{p} / \mathrm{s} / \mathrm{cm}^{2} / \mathrm{sr}\right)$.

\section{Viability of encapsulated cells}

The viability of cells encapsulated in the undoped and HA-doped scaffolds was assessed by first casting $0.06 \mathrm{~mL}$ cell-loaded scaffolds, as described above, in 96 well tissue 
culture plates (Costar, Corning Inc., Corning, NY, USA). One and two days after polymerization, the viability of cells encapsulated in the scaffolds was assessed using the alamarBlue assay (Life Technologies) according to the manufacturer's instructions. Fluorescence measurements $\left(\lambda_{\mathrm{ex}}=560 \mathrm{~nm}, \lambda_{\mathrm{em}}=585 \mathrm{~nm}\right)$ of the samples were taken with a plate reader (SpectraMax M2e, Sunnyvale, CA, USA).

\section{Statistics}

Data are expressed as mean \pm standard deviation for the listed number of replicates per experimental group. Statistically significant differences between experimental groups was determined using a Student's $t$-test, with differences deemed significant for $p<0.05$.

\section{Results and Discussion}

Acoustic properties of fibrin scaffolds

A photograph of the fibrin scaffolds made for acoustic properties testing is shown in Fig. 1a (left). Undoped fibrin scaffolds were transparent whereas the HA-doped gels were opaque when the concentration of $\mathrm{HA}$ was $0.2 \%(w / v)$ or higher. As seen in Fig. 1a (right), HA aggregation was observed during and after fibrin polymerization if FBS was omitted in scaffold formulations containing $1 \%(w / v)$ or greater HA. B-mode images of scaffolds without $\mathrm{HA}$, with both HA and FBS, and with HA but without FBS are shown in Fig. 1b. Undoped scaffolds were hypoechoic whereas inclusion of HA in the scaffold caused an increase in echogenicity.

The measured speed of sound and attenuation of olive oil were $1453.5 \pm 3.7 \mathrm{~m} / \mathrm{s}$ and $0.45 \pm 0.07 \mathrm{~dB} / \mathrm{cm} / \mathrm{MHz}$, respectively. At the same temperature, previous studies obtained a speed of sound of $1438 \mathrm{~m} / \mathrm{s}$ (Treeby, et al. 2009) or $1452 \mathrm{~m} / \mathrm{s}$ (Benedito, et al. 2002) and an attenuation of $0.42 \mathrm{~dB} / \mathrm{cm} / \mathrm{MHz}$ (Chanamai and McClements 1998) or $0.47 \mathrm{~dB} / \mathrm{cm} / \mathrm{MHz}$ (Treeby, 
et al. 2009). The acoustic properties of undoped fibrin scaffolds are shown in Fig. 1c. Speed of sound and attenuation were directly proportional to fibrin concentration, which is similar to trends observed with polyacrylamide (Prokop, et al. 2003). The ability of cells to infiltrate and remodel a fibrin scaffold, which can facilitate regenerative processes such as angiogenesis, is inversely related to fibrin concentration (Kniazeva, et al. 2011). Fibrin concentrations of $2 \%$ (w/v) or less are commonly used in tissue engineering applications. Acoustic properties for the lowest density fibrin scaffold (i.e., $0.5 \% \mathrm{w} / \mathrm{v}$ ) were higher than values for water at $24.5^{\circ} \mathrm{C}$ (i.e., $1495.3 \mathrm{~m} / \mathrm{s}$ (Del Grosso and Mader 1972) and $0.015 \mathrm{~dB} / \mathrm{cm} / \mathrm{MHz}$ (Krautkra $\square$ mer and Krautkra $\square$ mer 1990)). The attenuation coefficients for all undoped fibrin scaffolds were lower than soft tissue (Culjat, et al. 2010) and clotted blood (Nahirnyak, et al. 2006), the latter of which contains fibrin as a major non-cellular component. Fig. 1d demonstrates that speed of sound and attenuation were inversely and directly proportional to HA concentration, respectively. A statistically significant decrease in speed of sound was observed at $5 \% \mathrm{HA}$, compared to $0 \%$ $H A$, whereas a significant increase in attenuation was observed at both $1 \%$ and $5 \% H A$, compared to $0 \%$ HA. A $1 \% \mathrm{w} / \mathrm{v}$ fibrin scaffold doped with $5 \% \mathrm{w} / \mathrm{v}$ HA had an attenuation coefficient similar to soft tissue.

\section{Induction of hyperthermia}

The temperature changes in undoped and HA-doped scaffolds after exposure to US at three acoustic intensities are displayed in Fig. 2. All acoustic intensities are expressed as spatial peak time average intensity (ISPTA). At the tested intensities, the maximum temperature changes in the HA-doped scaffold with $1 \% \mathrm{w} / \mathrm{v}$ fibrin and $5 \% \mathrm{w} / \mathrm{v} \mathrm{HA}$ ranged from $3.0-7.8^{\circ} \mathrm{C}$ and 1.9 $3.9^{\circ} \mathrm{C}$ when the transducer focus was positioned at a distance of $0 \mathrm{~mm}$ and $1 \mathrm{~mm}$, respectively, from the thermocouple. Comparatively, the maximum temperature change in the undoped fibrin scaffolds ranged from $0.9-2.5^{\circ} \mathrm{C}$ (profiles not shown) and $0.3-0.5^{\circ} \mathrm{C}$ at distances of $0 \mathrm{~mm}$ and 1 $\mathrm{mm}$, respectively. Overall, the rate of heating within a material is directly proportional to the 
attenuation and inversely proportional to the specific heat (Parker 1983). Thus, the observed temperature profiles are consistent with the differences in attenuation seen in Fig. 1d. Additionally, the lower heat capacity of HA (i.e., 662 - $1543 \mathrm{~J} / \mathrm{kg} / \mathrm{K}$ (Coelho, et al. 2007, Suda, et al. 1995)) compared to water (i.e., $4178 \mathrm{~J} / \mathrm{kg} / \mathrm{K}$ ), the major component of a fibrin scaffold, likely facilitates greater heating in the doped scaffolds.

\section{Induction of transgene expression}

The spatial localization of $f L u c$ expression within a HA-doped fibrin scaffold containing C3H10T1/2-fLuc cells is shown in Fig. 3a (top). Each row of focal transgene expression consists of three exposures at the same acoustic intensity. As seen in Fig. 3a (bottom), fLuc expression was observed in the entire cross section of the scaffold. The relationship between fLuc activity and acoustic intensity is displayed in Fig. 3b. In HA-doped scaffolds, 2 min or 5 min continuous wave US exposures with an $I_{\text {SPTA }}$ in the range of $26-50 \mathrm{~W} / \mathrm{cm}^{2}$ or $14-30 \mathrm{~W} / \mathrm{cm}^{2}$, respectively, generated $f L u c$ expression. The average and maximum radiances ranged from 0.4-1.4 $\times 10^{5} \mathrm{p} / \mathrm{s} / \mathrm{cm}^{2} / \mathrm{sr}$ and $1.5-3.6 \times 10^{5} \mathrm{p} / \mathrm{s} / \mathrm{cm}^{2} / \mathrm{sr}$ for 2 min exposures and from $0.8-7.4 \times 10^{4}$ $\mathrm{p} / \mathrm{s} / \mathrm{cm}^{2} / \mathrm{sr}$ and $0.3-1.9 \times 10^{5} \mathrm{p} / \mathrm{s} / \mathrm{cm}^{2} / \mathrm{sr}$ for $5 \mathrm{~min}$ exposures, respectively. Comparatively, in the undoped scaffold with the same fibrin density, the threshold to detect $f L u c$ expression using bioluminescence imaging was a 5 min continuous wave US exposure at $35 \mathrm{~W} / \mathrm{cm}^{2}$ - as is evident with the plot of maximum radiance in Fig. 3b. Thus, significantly greater transgene expression, quantified using average and maximum radiances, was obtained in the doped versus undoped scaffold at a given acoustic intensity. In our previous study utilizing the same US transducer and undoped scaffolds with $1 \% \mathrm{w} / \mathrm{v}$ fibrin, fLuc expression was observed with 5 to $15 \mathrm{~min}$ continuous wave US exposures and ISPTA of 658 to $850 \mathrm{~W} / \mathrm{cm}^{2}$; the average and maximum radiances ranged from $3.0-5.5 \times 10^{4} \mathrm{p} / \mathrm{s} / \mathrm{cm}^{2} / \mathrm{sr}$ and $1.3-1.9 \times 10^{5} \mathrm{p} / \mathrm{s} / \mathrm{cm}^{2} / \mathrm{sr}$, respectively, with a 5 min exposure (Wilson, et al. 2014). In the same study, a maximum temperature 
increase of $8^{\circ} \mathrm{C}$ was measured in the undoped scaffold immediately after a 10 min US exposure with an ISPTA of $658 \mathrm{~W} / \mathrm{cm}^{2}$.

\section{Viability of encapsulated cells}

The metabolic activity of C3H10T1/2-fLuc encapsulated in undoped and HA-doped fibrin scaffolds is displayed in Fig. 4. No statistically significant differences were observed between undoped and doped scaffolds. Based on the linear regression in Fig. 4a, the cell density in the HA doped scaffolds ranged from $1.01-1.03 \times 10^{6}$ cells $/ \mathrm{mL}$, compared to $10^{6}$ cells $/ \mathrm{mL}$ in the undoped scaffolds. This biocompatibility is consistent with previous cell studies utilizing HAdoped fibrin scaffolds (Kidd, et al. 2012, Rao, et al. 2014). In a previous study, no significant differences in cellular metabolic activity were observed for C3H10T1/2-fLuc cells encapsulated in undoped fibrin scaffolds when exposed to 5 to 15 min continuous wave US exposures with an ISPTA of $754 \mathrm{~W} / \mathrm{cm}^{2}$, compared to cells not exposed to US (Wilson, et al. 2014).

\section{Conclusions}

The acoustic attenuation of fibrin can be increased significantly via the inclusion of HA nanopowder, with a $1 \%(\mathrm{w} / \mathrm{v})$ fibrin scaffold doped with $5 \%(\mathrm{w} / \mathrm{v}) \mathrm{HA}$ displaying an attenuation similar to soft tissue. Correspondingly, a greater elevation in temperature was generated in the doped scaffolds, compared to the undoped scaffolds, for a given acoustic intensity. Transgene activation of cells harboring a heat-inducible gene switch occurred at lower acoustic intensities and shorter exposure times when the cells were encapsulated in HA-doped scaffolds, compared to undoped fibrin scaffolds. Cell viability was not affected by the inclusion of HA within the fibrin scaffold. The presented findings have broad applicability within the field of gene therapy, especially in tissue regeneration where cells are commonly encapsulated in hydrogel scaffolds and subsequently implanted for the repair of tissue defects. 


\section{Acknowledgments}

This work was supported by DOD grant W81XWH-10-1-0992 (RTF), NIH grant R21AR065010 (MLF), and funds from the University of Michigan MCubed Program (JBF, RTF). AM is supported by the National Science Foundation Graduate Student Research Fellowship (DGE 1256260). 


\section{References}

Benedito J, Mulet A, Velasco J, Dobarganes MC. Ultrasonic assessment of oil quality during frying. J Agr Food Chem 2002; 50:4531-36.

Chanamai R, McClements DJ. Ultrasonic attenuation of edible oils. J Am Oil Chem Soc 1998; 75:1447-48.

Coelho TM, Nogueira ES, Weinand WR, Lima WM, Steimacher A, Medina AN, Baesso ML, Bento AC. Thermal properties of natural nanostructured hydroxyapatite extracted from fish bone waste. J Appl Phys 2007; 101.

Culjat MO, Goldenberg D, Tewari P, Singh RS. A review of tissue substitutes for ultrasound imaging. Ultrasound Med Biol 2010; 36:861-73.

Deckers R, Quesson B, Arsaut J, Eimer S, Couillaud F, Moonen CTW. Image-guided, noninvasive, spatiotemporal control of gene expression. P Natl Acad Sci USA 2009; 106:1175-80.

Del Grosso VA, Mader CW. Speed of Sound in Pure Water. Journal of the Acoustical Society of America 1972; 52:1442-46.

Eker OF, Quesson B, Rome C, Arsaut J, Deminiere C, Moonen CT, Grenier N, Couillaud F. Combination of Cell Delivery and Thermoinducible Transcription for in Vivo Spatiotemporal Control of Gene Expression: A Feasibility Study. Radiology 2011; 258:496-504.

Escoffre JM, Novell A, de Smet M, Bouakaz A. Focused ultrasound mediated drug delivery from temperature-sensitive liposomes: in-vitro characterization and validation. Physics in medicine and biology 2013; 58:8135-51.

Franckena M, Lutgens LC, Koper PC, Kleynen CE, van der Steen-Banasik EM, Jobsen JJ, Leer JW, Creutzberg CL, Dielwart MF, van Norden Y, Canters RAM, van Rhoon GC, van der Zee J. Radiotherapy and Hyperthermia for Treatment of Primary Locally Advanced Cervix Cancer: Results in 378 Patients. Int J Radiat Oncol 2009; 73:242-50.

Friedl J, Turner E, Alexander HR. Augmentation of endothelial cell monolayer permeability by hyperthermia but not tumor necrosis factor: Evidence for disruption of vascular integrity via VE-cadherin down-regulation. Int J Oncol 2003; 23:611-16.

Kidd ME, Shin S, Shea LD. Fibrin hydrogels for lentiviral gene delivery in vitro and in vivo. Journal of Controlled Release 2012; 157:80-85.

Kniazeva E, Kachgal S, Putnam AJ. Effects of Extracellular Matrix Density and Mesenchymal Stem Cells on Neovascularization In Vivo. Tissue Eng Pt A 2011; 17:905-14.

Krautkra $\square$ mer J, Krautkra $\square$ mer H. Ultrasonic testing of materials. Berlin ; New York: SpringerVerlag, 1990.

Liu Y, Williams DJ. Incorporation of Hydroxyapatite Sol Into Collagen Gel to Regulate the Contraction Mediated by Human Bone Marrow-Derived Stromal Cells. leee T Nanobiosci 2010; 9:1-11.

Lu X, Sankin G, Pua EC, Madden J, Zhong P. Activation of transgene expression in skeletal muscle by focused ultrasound. Biochemical and biophysical research communications 2009; 379:428-33.

Martin-Saavedra FM, Wilson CG, Voellmy R, Vilaboa N, Franceschi RT. Spatiotemporal control of vascular endothelial growth factor expression using a heat-shock-activated, rapamycin-dependent gene switch. Human gene therapy methods 2013; 24:160-70.

Nahirnyak VM, Yoon SW, Holland CK. Acousto-mechanical and thermal properties of clotted blood. Journal of the Acoustical Society of America 2006; 119:3766-72.

Parker KJ. Ultrasonic-Attenuation and Absorption in Liver-Tissue. Ultrasound Med Biol 1983; 9:363-69.

Ping $\mathrm{H}$. Direct measurement of ultrasonic dispersion using a broadband transmission technique. Ultrasonics 1999; 37:67-70. 
Plathow C, Lohr F, Divkovic G, Rademaker G, Farhan N, Peschke P, Zuna I, Debus J, Claussen CD, Kauczor HU, Li CY, Jenne J, Huber P. Focal gene induction in the liver of rats by a heat-inducible promoter using focused ultrasound hyperthermia - Preliminary results. Invest Radiol 2005; 40:729-35.

Prokop AF, Vaezy S, Noble ML, Kaczkowski PJ, Martin RW, Crum LA. Polyacrylamide gel as an acoustic coupling medium for focused ultrasound therapy. Ultrasound Med Biol 2003; 29:1351-58.

Ranjan A, Jacobs GC, Woods DL, Negussie AH, Partanen A, Yarmolenko PS, Gacchina CE, Sharma KV, Frenkel V, Wood BJ, Dreher MR. Image-guided drug delivery with magnetic resonance guided high intensity focused ultrasound and temperature sensitive liposomes in a rabbit Vx2 tumor model. Journal of Controlled Release 2012; 158:487-94.

Rao RR, Ceccarelli J, Vigen ML, Gudur M, Singh R, Deng CX, Putnam AJ, Stegemann JP. Effects of hydroxyapatite on endothelial network formation in collagen/fibrin composite hydrogels in vitro and in vivo. Acta Biomater 2014; 10:3091-7.

Selfridge AR. Approximate Material Properties in Isotropic Materials. leee T Son Ultrason 1985; 32:381-94.

Smith RC, Machluf M, Bromley P, Atala A, Walsh K. Spatial and temporal control of transgene expression through ultrasound-mediated induction of the heat shock protein $70 \mathrm{~B}$ promoter in vivo. Hum Gene Ther 2002; 13:697-706.

Song CW, Park HJ, Lee CK, Griffin R. Implications of increased tumor blood flow and oxygenation caused by mild temperature hyperthermia in tumor treatment. Int $\mathrm{J}$ Hyperther 2005; 21:761-67.

Suda H, Yashima M, Kakihana M, Yoshimura M. Monoclinic[--]Hexagonal Phase-Transition in Hydroxyapatite Studied by X-Ray-Powder Diffraction and Differential Scanning Calorimeter Techniques. J Phys Chem-Us 1995; 99:6752-54.

Treeby BE, Cox BT, Zhang EZ, Patch SK, Beard PC. Measurement of Broadband TemperatureDependent Ultrasonic Attenuation and Dispersion Using Photoacoustics. leee T Ultrason Ferr 2009; 56:1666-76.

Urano M, Kuroda M, Nishimura Y. For the clinical application of thermochemotherapy given at mild temperatures. Int J Hyperther 1999; 15:79-107.

Wilson CG, Martin-Saavedra FM, Padilla F, Fabiilli ML, Zhang M, Baez AM, Bonkowski CJ, Kripfgans OD, Voellmy R, Vilaboa N, Fowlkes JB, Franceschi RT. Patterning expression of regenerative growth factors using high intensity focused ultrasound. Tissue engineering. Part C, Methods 2014; 20:769-79.

Xu L, Zhao Y, Zhang Q, Li Y, Xu Y. Regulation of transgene expression in muscles by ultrasound-mediated hyperthermia. Gene therapy 2004; 11:894-900. 
Figure 1. A) Photographs of the undoped and HA-doped scaffolds with $1 \%(w / v)$ fibrin. Scaffolds in the left image contain FBS whereas those in the right image do not contain FBS. The HA concentration (\% w/v) is listed for each sample. Scale bar: $10 \mathrm{~mm}$. B) B-mode images of $1 \%(w / v)$ fibrin scaffolds without HA (left), with both HA and FBS (middle), and with HA but without FBS (right). The HA concentration (\% w/v) is listed for each sample. Scale bar: $10 \mathrm{~mm}$. C) Speed of sound and attenuation ( $n=3$ sample pairs with 5 measurements in each sample) of undoped fibrin scaffolds. ${ }^{*} p<0.05$. D) Speed of sound and attenuation $(\mathrm{n}=3$ sample pairs with 5 measurements in each sample) of HA-doped fibrin scaffolds containing $1 \%(w / v)$ fibrin. ${ }^{*} p<0.05$ vs. $0 \%$ HA.

Figure 2. Time course of temperature rises within HA-doped $(\mathbf{A}, \mathbf{B})$ and undoped $(\mathbf{C})$ scaffolds with $1 \%(\mathrm{w} / \mathrm{v})$ fibrin. HA-doped scaffolds contained $5 \%(\mathrm{w} / \mathrm{v}) \mathrm{HA}$. In panel $\mathrm{A}$, the focus of the HIFU transducer was positioned at the tip of thermocouple, whereas in panels $\mathrm{B}$ and $\mathrm{C}$, the focus was shifted $1 \mathrm{~mm}$ with respect to the thermocouple. Continuous wave US was applied starting at $10 \mathrm{~s}$ for either $120 \mathrm{~s}\left(\mathrm{I}_{\text {SPTA }}=50.4 \mathrm{~W} / \mathrm{cm}^{2}\right)$ or $300 \mathrm{~s}\left(\mathrm{I}_{\text {SPTA }}=19.1 \mathrm{~W} / \mathrm{cm}^{2}\right.$ or $\left.26.2 \mathrm{~W} / \mathrm{cm}^{2}\right)$. Note the difference in scale of the temperature change in $A$ and $B$ versus $C$.

Figure 3. A) Bioluminescence image of a $1 \%(\mathrm{w} / \mathrm{v})$ fibrin scaffold doped with $5 \% \mathrm{HA}$ and containing $\mathrm{C} 3 \mathrm{H} 10 \mathrm{~T} 1 / 2-f L u c$ cells. The previous day, spatially-localized regions of hyperthermia were generated in a $3 \times 3$ grid pattern using 2 min continuous wave exposures of focused US (top). The I I reveals that transgene activation occurred throughout the entire scaffold thickness. To aid in imaging, the sectioned scaffold was placed adjacent to the edge of the culture dish. Scale bar: $5 \mathrm{~mm}$. B) Effect of acoustic intensity and exposure on fLuc expression in fibrin scaffolds containing $\mathrm{C} 3 \mathrm{H} 10 \mathrm{~T} 1 / 2-f L u c$ cells ( $\mathrm{n}=3$ per time point). The average (Avg) and maximum (Max) radiance for each exposure condition is displayed. 
Figure 4. A) Metabolic activity of C3H10T1/2-fLuc cells encapsulated in $1 \%(\mathrm{w} / \mathrm{v})$ fibrin scaffolds. B) Metabolic activity of C3H10T1/2-fLuc cells encapsulated in $1 \%(\mathrm{w} / \mathrm{v})$ fibrin scaffolds $\left(10^{6}\right.$ cells $\left./ \mathrm{mL}\right)$ containing varying amounts of $\mathrm{HA}$. All data are shown as mean \pm standard deviation of $n=5$ scaffolds per time point. 
Figure 1
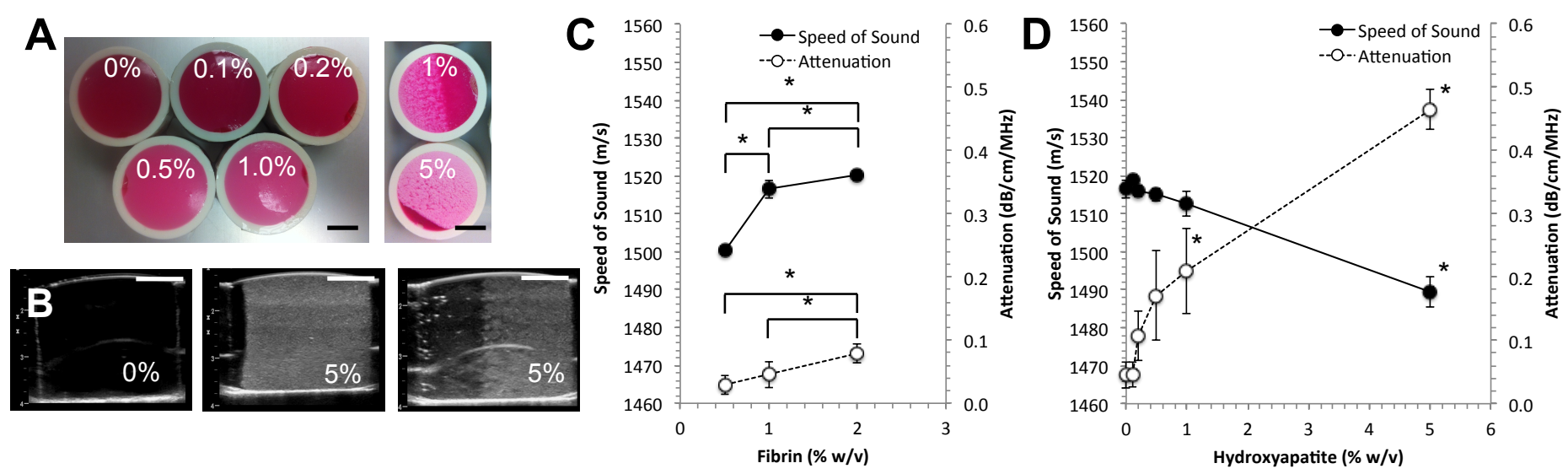
Figure 2

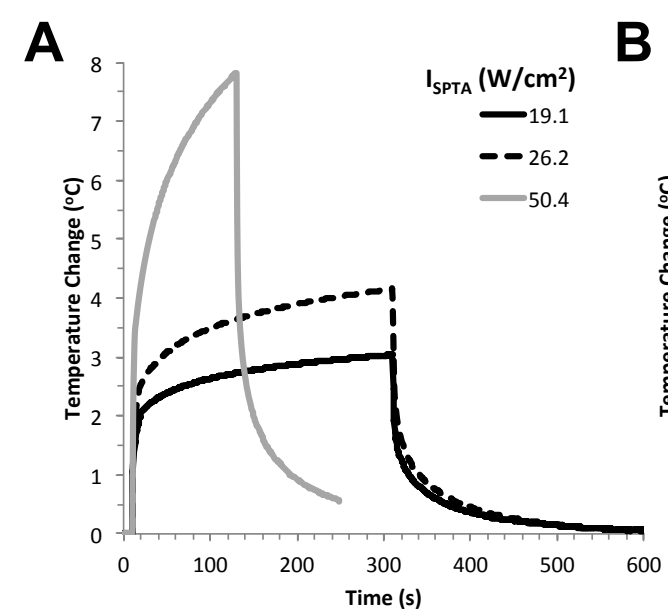

B

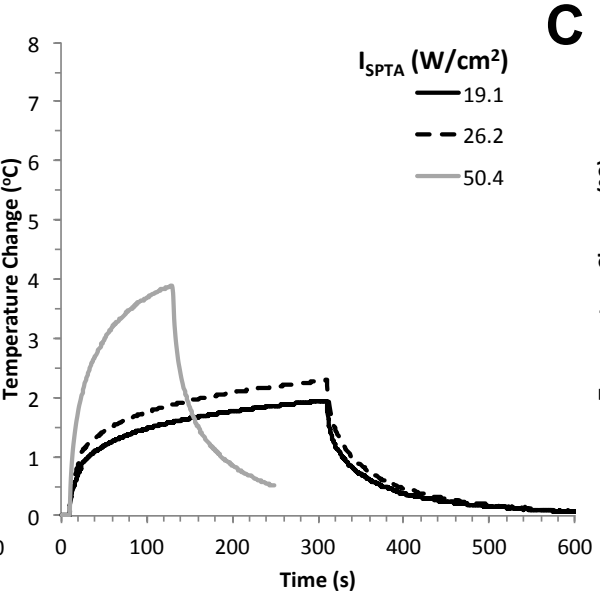

C

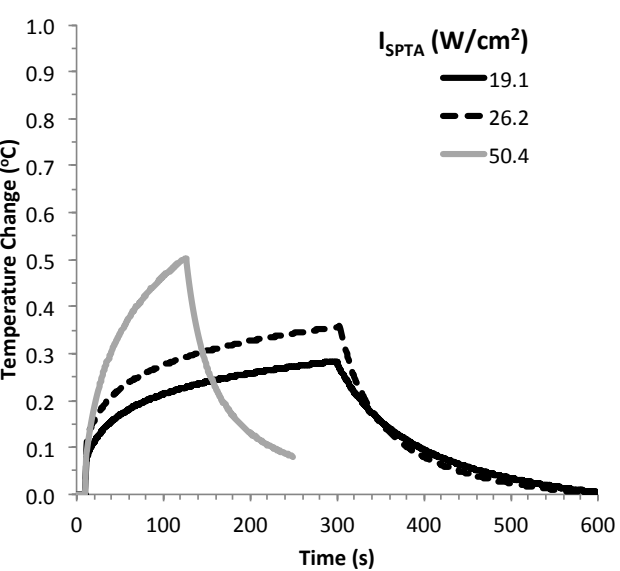


Figure 3

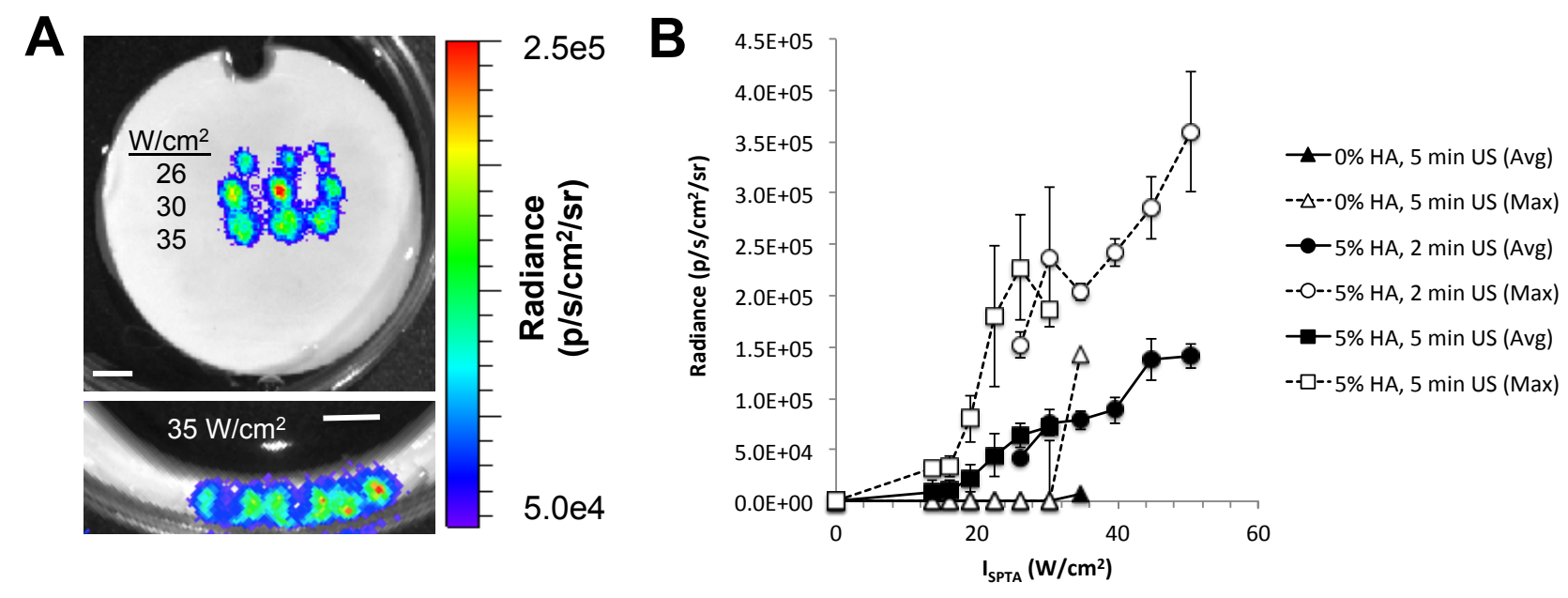


Figure 4
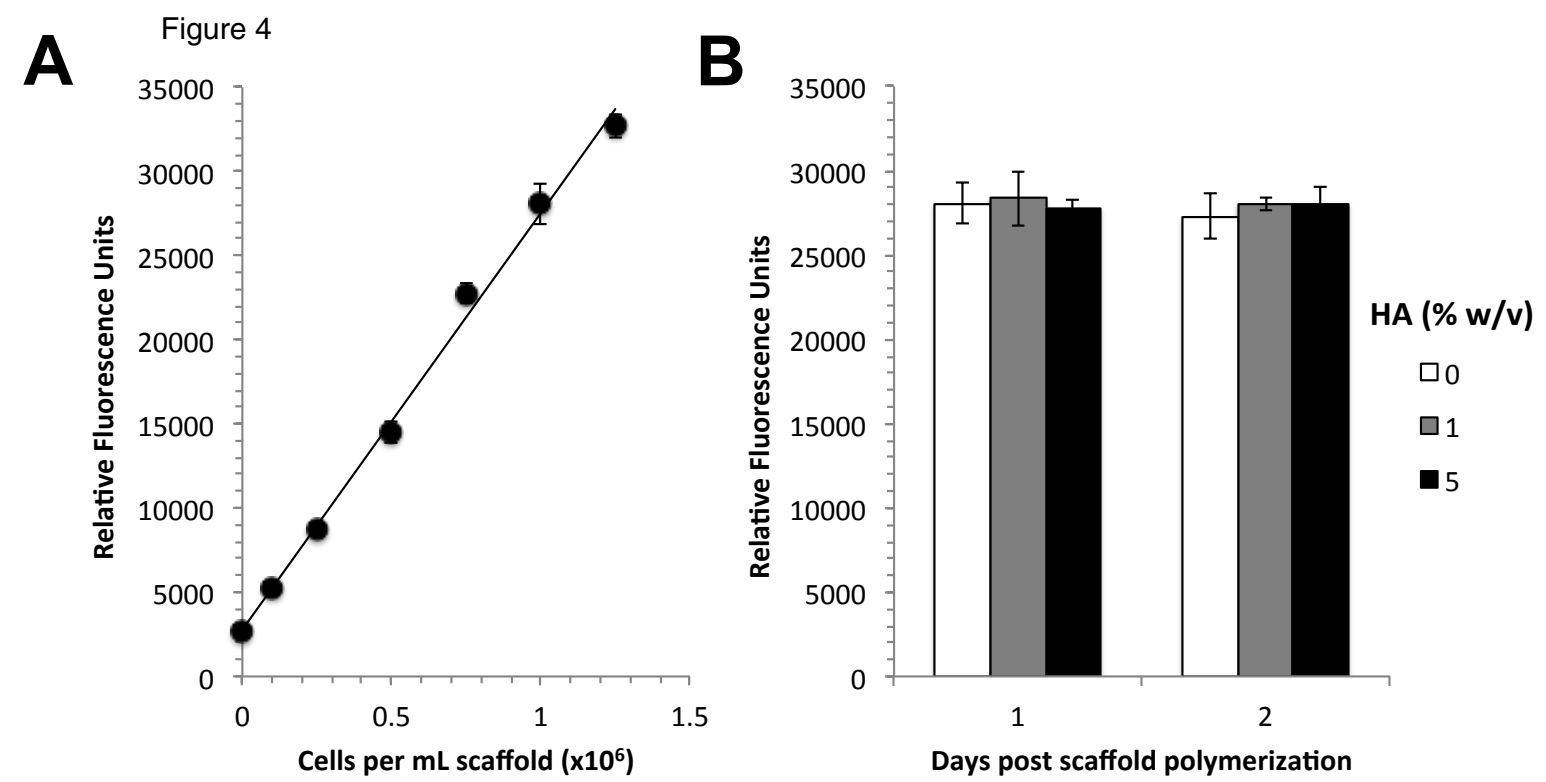